\title{
A CORRELAÇÃO ENTRE SANEAMENTO BÁSICO E INFECÇÕES POR SARS-COV-2: REVISÃO NARRATIVA
}

Saúde Coletiva/Epidemiologia

\section{UNIVERSIDADE NOVE DE JULHO \\ Curso de Medicina}

Costa, $\left.\right|^{1}$

Rodrigues, $\mathbf{M ~ Y}^{1}$

Zamuner, $\mathbf{S}^{2}$

Rua Itacuruça, № 40; Cel.+55(11) 9471-48195; contato: isabela.padula@uni9.edu.br

São Paulo

2021 


\section{A CORRELAÇÃO ENTRE SANEAMENTO BÁSICO E INFECÇÕES POR SARS-COV-2: REVISÃO NARRATIVA}

Saúde Coletiva/Epidemiologia

Descritores: Infecção por coronavírus, saneamento básico, SARS-CoV-2, Pandemia 


\section{RESUMO}

INTRODUÇÃO: No dia 30 de janeiro de 2020 a OMS anunciou o estado de pandemia por conta do número crescente de casos pelo mundo de COVI-19. Exames como o RT-PCR estão sendo utilizados para diagnosticar a infecção pelo SARS-CoV-2, a partir da coleta por swab de secreção orofaríngea. Todavia, recentes estudos sobre o exame RT-PCR provaram que o RNA viral estava presente em espécimes fecais, apresentando a forma contaminante do vírus por até 96 horas. Diante desse resultado surgem preocupações quanto ao aumento da transmissibilidade desse vírus pela via oral-fecal, principalmente em países subdesenvolvidos, os quais sofrem com a precarização do saneamento básico, como é o caso do Brasil. Assim sendo, o artigo em questão, tem como objetivo avaliar a relação entre a condição de saneamento básico no Brasil e a distribuição de casos de COVID-19 no contexto da pandemia.

METODOLOGIA: Trata-se de uma revisão narrativa da literatura. Foram utilizados artigos encontrados nas bases de dados PubMed, Biblioteca Virtual de Saúde (BVS) e sciELO, através dos descritores "infecções por coronavírus", "saneamento básico". Só foram utilizados artigos com datas de publicação dos anos de 2019 e 2020 e aqueles que entravam nos critérios de inclusão e exclusões já pré-determinados

RESULTADOS: Identificou-se um total de 47 artigos a partir do uso dos descritores, nas bases de dados citadas, das quais 25 foram retirados da BVS, 18 do PubMed e 14 da Scielo. Após a eliminação de artigos a partir dos critérios de inclusão e exclusão prédeterminados resultou um total de 11 artigos que foram usados para a confecção deste estudo. Dos quais quatro tinham como objetivo relacionar o baixo índice de saneamento com o possível aumento dos casos de infecção por COVID-19. Quatro propuseram resoluções ou indicações para reduzir a contaminação por SARS-CoV-2 no geral. Dois estudos avaliaram a sobrevida do vírus no trato gastrointestinal e no esgoto. E por fim, um artigo relaciona o aumento da emissão de poluentes com o aumento dos casos de COVID19.

CONCLUSÃO: Pode-se afirmar que a falta de investimentos governamentais em garantir de forma integral o acesso ao saneamento básico e a água tratada vem prejudicando a saúde da população e aumentando consideravelmente a chances de contaminação pelas diferentes vias do vírus responsável pela pandemia de COVID-19. 


\section{SUMÁRIO}

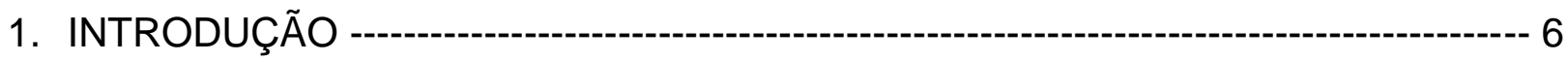

2. JUSTIFICATIVA --- 8

3. OBJETIVO --- 9

4. METODOLOGIA -- 10

5. RESULTADOS - 11

6. DISCUSSÃO - 15

6.1 Transmissibilidade do SARS-CoV-2 pelas fezes e riscos associados ------------ 15

6.2 A precariedade das condições de saneamento e os grupos de risco durante a pandemia ------------------------------------------------------------15

6.3 O saneamento básico e as possíveis formas para evitar a disseminação do SARSCoV-2 --- 16

7. CONCLUSÃO - 18

REFERENCIAS --- 


\section{A CORRELAÇÃO ENTRE SANEAMENTO BÁSICO E INFECÇÕES POR SARS-COV-2: REVISÃO NARRATIVA}

\section{INTRODUÇÃO}

No dia 31 de dezembro de 2019 a China anunciou o primeiro caso de COVID-19 (Coronavírus Disease 2019), doença causada por uma nova cepa do vírus da família Coronaviridae e gênero beta coronavírus que foi denominado SARS-CoV-2 $(1,2)$. Número crescentes de casos foram confirmados desde essa data, levando a Organização Mundial da Saúde (OMS) a anunciar estado de pandemia em 30 de janeiro de 2020, visto que 206 países apresentaram casos da doença, fato que tem ameaçado a saúde da população mundial, já que é a COVID-19 possui uma alta infectividade e morbidade (3).

O Coronavírus é um vírus de origem zoonótica com RNA fita simples envelopado que já causou duas pandemias. Em 2002, foi identificado em Guangdong (China), uma variante agressiva do coronavírus, a Síndrome Respiratória Aguda Grave Coronavírus (SARS-CoV) responsável por mais de 8000 casos confirmados, 774 mortes em 37 países. Após esse episódio, em 2012, foi identificado na Arábia Saudita a MERS-CoV, causador da Síndrome Respiratória do Oriente Médio (4).

O primeiro caso da doença no Brasil foi diagnosticado em fevereiro de 2020, em São Paulo. Foi um paciente do sexo masculino com histórico de viagem recente para a Itália, onde já havia casos confirmados da COVID-19 ${ }_{(5)}$. Até o momento, a América é a região com maior número de casos confirmados, sendo o Brasil o país com a segunda maior representatividade (4,147,794 casos), ficando atrás somente dos Estados Unidos da América $(6,248,989$ casos). Até o momento, não há vacinas nem medicamentos específicos para o vírus, somente ensaios clínicos que visam determinar formas de prevenção e tratamento da doença (3).

No atual cenário pandêmico, pacientes infectados com o novo SARS-CoV-2 apresentam como principais manifestações clínicas a febre, tosse, fadiga, dispneia, mialgia, produção de escarro e dor de cabeça, sendo outros sintomas como náusea, vômito e diarreia menos comuns (3). A transmissão pode ocorrer de forma direta e indireta. A forma direta ocorre através do contato com gotículas respiratórias que são expelidas quando um indivíduo infectado tosse, fala, canta, espirra etc. Já a forma indireta ocorre quando uma pessoa é exposta a superfícies contaminadas e o vírus entra em contato com mucosas, como olhos, nariz e boca (6).

Nesse contexto, alguns tipos de testes foram usados para o diagnóstico da infecção por coronavírus. Entre eles, há o exame RT-PCR (reverse-transcriptase polymerase chain reaction) que se tornou o padrão ouro, pois detecta a presença de carga viral a partir de material genético presente na secreção respiratória até os primeiros 12 dias em que os pacientes estão sintomáticos. O RT-PCR é realizado a partir da coleta por swab de secreção orofaríngea, o qual usa técnicas biomoleculares para quantificar o material genético do vírus $(7)$.

Os recentes estudos sobre o exame RT-PCR provaram que o RNA viral estava presente em espécimes fecais, além de apresentar a forma infectante da COVID-19 por até 96 horas $(8,9)$. Com isso surgem alguns questionamentos quanto à possibilidade da contaminação pela via fecal-oral, uma vez que em 2003 foi constatado uma falha no esgotamento de Hong Kong que pode ter facilitado a transmissão do SARS. Tal fato corrobora a hipótese de que o sistema de esgotamento sanitário poderia atuar como vetor 
do microrganismo causador da COVID-19. Ademais, experiências realizadas durante 0 surto de MERS-CoV e SARS-CoV mostraram semelhança genética com o SARS-CoV-2 $(8,10,11)$.

Diante desses resultados, a indicação da presença do RNA viral nas fezes gera preocupações quanto ao aumento da transmissibilidade por essa via, sobretudo para países como o Brasil, cujos índices de saneamento básico não atingem toda a população. De acordo com a Pesquisa Nacional de Saneamento Básico (PNSB) de 2017, realizada pelo Instituto Brasileiro de Geografia e Estatística (IBGE), cerca da metade dos domicílios permanecem sem coleta de esgoto, o que evidencia o déficit no saneamento básico e acessibilidade desproporcional entre as diferentes regiões do país (10). Esse cenário se mostra contraditório, haja vista a Lei Nacional de Saneamento Básico, promulgada em 2007, que estabelece diretrizes nacionais de saneamento e prevê, sobretudo, a universalidade do acesso a tais serviços (12).

O termo "saneamento" é conceituado pela OMS como "o gerenciamento dos fatores físicos que é capaz de exercer efeitos nocivos sobre o homem, no âmbito do bem-estar físico, mental e social". Assim, considerando-se que a mesma instituição define saúde como "um estado de completo bem-estar físico, mental e social e não somente ausência de afecções e enfermidade", o controle desses fatores físicos a partir do saneamento mostrase, portanto, essencial na saúde preventiva (12). Tal relação permite intervenções que visem atuar sobre determinantes de saúde e no processo saúde-doença de inúmeras enfermidades, como a COVID-19.

Nessa perspectiva, considerando as medidas de prevenção propostas pela OMS para a COVID-19 e para outras infecções respiratórias - que são essencialmente a higienização das mãos com água e sabão (mais indicado) ou com álcool em gel, etiqueta respiratória, o uso de máscara para indivíduos sintomáticos, distanciamento social, entre outros - é notório que a deficiência na coleta de esgoto pode significar um risco aumentado para a infecção por coronavírus, além de a falta de acesso à água tratada dificultar o cumprimento das medidas de higienes propostas pela OMS, como medida de contenção da doença (5).

Assim sendo, o objetivo do presente artigo é revisar os possíveis impactos da deficiência do saneamento básico sobre enfrentamento da pandemia da COVID-19 no Brasil. 
2. JUSTIFICATIVA

Diante do atual cenário de pandemia e das condições sanitárias do Brasil, onde o acesso ao saneamento básico de uma parcela significativa da população ainda é precário e desigual, é relevante o estudo da relação desses fatores com a distribuição de casos da COVID-19. A presente pesquisa possibilita pensar em intervenções apropriadas que visem diminuir o contágio nesse público que se encontra em situação de vulnerabilidade social. 
3. OBJETIVOS

O artigo em questão tem como finalidade avaliar a relação entre a condição de saneamento básico no Brasil e a possibilidade de contágio através da via oral-fecal em contexto de pandemia pela COVID-19. 


\section{METODOLOGIA}

Trata-se de uma revisão narrativa da literatura norteada pelo método PRISMA. Foram utilizados artigos encontrados nas bases de dados Medical Literature Analysis and Retrieval System Online (MEDLINE) via PubMed, Biblioteca Virtual de Saúde (BVS) e SciELO.

Para a busca desses artigos foram utilizados como descritores DeCs da BVS e sciELO: "infecções por coronavírus" e "saneamento básico" e MeSH no PUBMED "coronavirus infection" and "basic sanitation". Também foram incluídos na pesquisa artigos que eram relevantes para a revisão.

Os critérios exclusão usados para selecionar os artigos foram: data de publicação, nos quais artigos que não foram publicados nos anos de 2019 a 2020 foram excluídos, publicações que não sê tratavam de artigos científicos, todos os estudos que não abordavam a transmissão do COVID-19, os que não relacionavam o vírus com saneamento básico de alguma forma ou aqueles que abordavam doenças ocasionadas por microrganismos diferentes do vírus pertencentes à família do coronaviridae. Também foram excluídos estudos que o título ou resumo destoam do objetivo do estudo em questão.

Os artigos identificados foram selecionados a partir dos critérios de inclusão e exclusão. Todos esses foram avaliados por dois revisores independentes os quais selecionaram os estudos por título e resumo, revisando aqueles com maior relevância para o estudo. Os dados extraídos das publicações foi o nome do autor principal, idioma, tipo de publicação, Base de dado que o estudo foi retirado, objetivo, método e resultado. para a o melhor aproveitamento desses dados foi criado uma tabela (tabela 1).

Foi feito um fluxograma representando o processo e as etapas de seleção das referências que foram incluídas nessa revisão da literatura (figura 1). 


\section{RESULTADOS}

Identificou-se um total de 47 referências nas bases de dados, das quais $25(53,2 \%)$ foram encontradas na BVS, $18(38,3 \%)$ na PubMed e $4(8,5 \%)$ na sciELO. Trinta e cinco (35) referências foram excluídas pelos critérios de exclusão pré-estabelecidos. Sendo utilizados para a confecção deste artigo um total de 11 estudos.

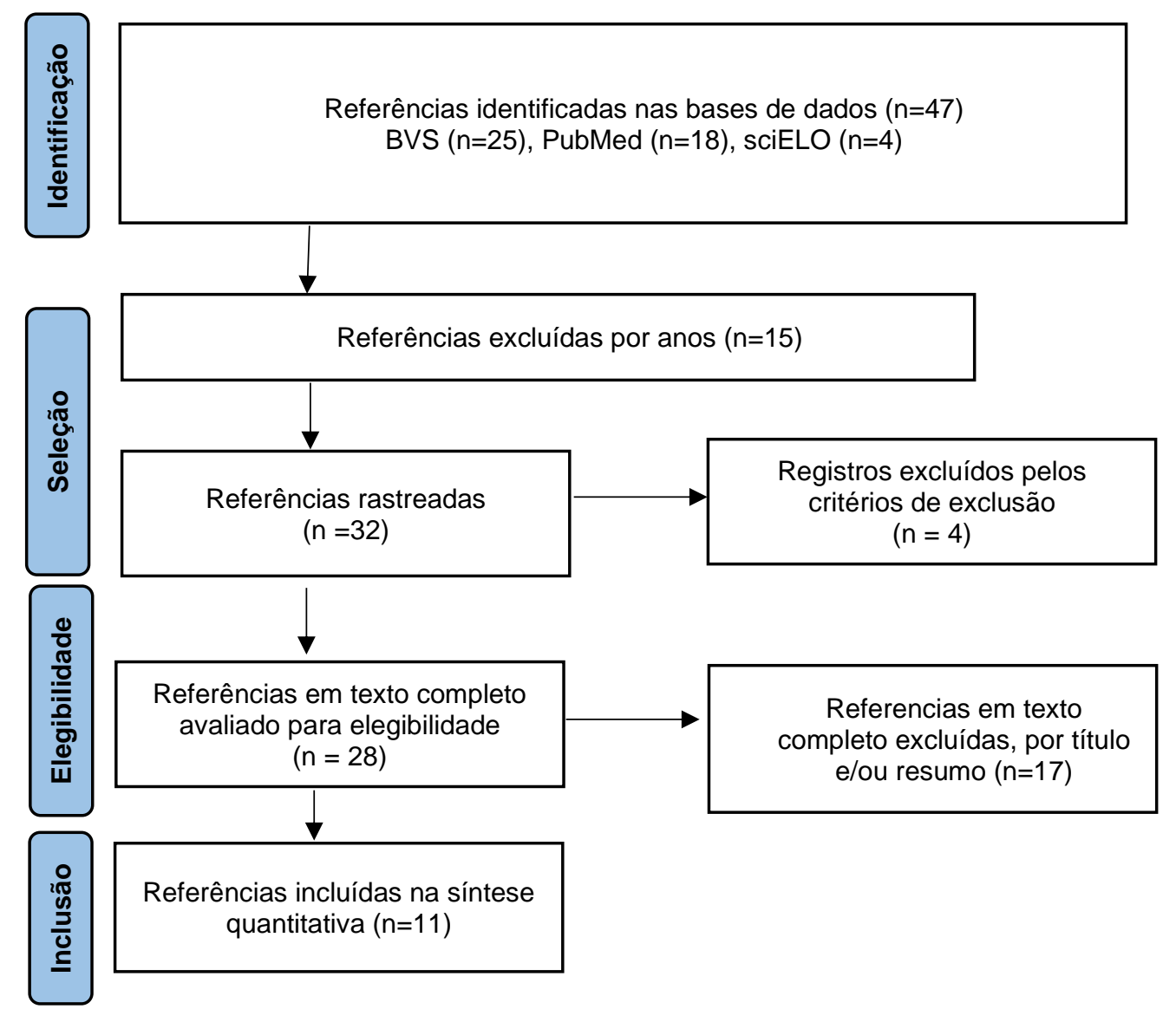

Figura 1: fluxograma representando o processo e as etapas de seleção das referências que foram incluídas na revisão da literatura. 


\begin{tabular}{|c|c|c|c|c|}
\hline Autor (ano) & $\begin{array}{c}\text { Tipos de } \\
\text { publicação }\end{array}$ & Idioma & Base de dados & Resultados/conclusão \\
\hline $\begin{array}{c}\text { Silva R } \\
\text { (4) } \\
2020-06-20\end{array}$ & Estudo ecológico & Inglês & Scielo & $\begin{array}{l}\text { Observou correlação } \\
\text { entre o número de } \\
\text { casos de COVID-19, } \\
\text { índice de mortalidade e } \\
\text { índice tratamento de } \\
\text { esgoto }\end{array}$ \\
\hline $\begin{array}{c}\text { Soares A } \\
2020-05-15\end{array}$ & Revisão sistemática & Português & Scielo & $\begin{array}{c}\text { Observou que poucos } \\
\text { estudos apontam para } \\
\text { o potencial de } \\
\text { contaminação de } \\
\text { COVID19 pelo esgoto } \\
\text { sanitário, mas análise } \\
\text { das pesquisas apontam } \\
\text { que essa proposição } \\
\text { deve ser considerada } \\
\text { nas ações de vigilância } \\
\text { para COVID-19 }\end{array}$ \\
\hline $\begin{array}{c}\text { Mesía V } \\
\text { (14) } \\
2020-05-21\end{array}$ & Documento técnico & Espanhol & BVS & $\begin{array}{l}\text { Observa que deve ser } \\
\text { adotada medidas de } \\
\text { distanciamento social } \\
\text { de acordo com o grau } \\
\text { de infecção por } \\
\text { COVID19, além disso } \\
\text { ressalta que deve ter } \\
\text { uma melhora na } \\
\text { situação atual do } \\
\text { saneamento básico } \\
\text { dessas regiões }\end{array}$ \\
\hline $\begin{array}{c}\text { Global } \\
\text { WASH } \\
\text { Cluster } \\
\text { (15) } \\
2020-08-05\end{array}$ & Resumo da política & Inglês & BVS & $\begin{array}{c}\text { Observou que para o } \\
\text { maior controle da } \\
\text { COVID19 deve ser } \\
\text { garantido o acesso } \\
\text { continuo a qualidade } \\
\text { dos serviços de WASH } \\
\text { (água, saneamento e } \\
\text { higiene) }\end{array}$ \\
\hline $\begin{array}{c}\text { Rollemberg } \\
\text { S } \\
(10) \\
2020-10-08\end{array}$ & $\begin{array}{l}\text { Revisão da } \\
\text { literatura }\end{array}$ & Português & PubMed & $\begin{array}{l}\text { Observou que o } \\
\text { CoviD-19 é sensível à } \\
\text { temperatura e as } \\
\text { condições do meio, por } \\
\text { isso tecnologias para } \\
\text { tratamento de esgoto e } \\
\text { água devem ser } \\
\text { utilizadas }\end{array}$ \\
\hline
\end{tabular}


World

Health

Organization Resumo Científico Inglês BVS

(16)

2020-06-09

Odih E

(17) Revisão sistemática Inglês BV 2020-08-09

Anser M

(18)

2020-08-15

Artigo Informativo

Inglês

PubMed

Christoffel M

(19)

2020-04-21

Mello R

(20)

2020-07-16

Artigo de revisão português

BVS

Mesoraca A

(6)

2020-06-30

Estudo Reflexivo Inglês

Scielo 
Os estudos selecionados para esta revisão foram publicados no período de 2019 a 2020 e que relacionaram a possibilidade da transmissão do coronavírus pelas fezes e águas residuais, além de compararem o aumento da transmissibilidade em países com baixo índice de saneamento básico.

Maior parte dos estudos encontrados estavam na língua inglesa $(n=7)$, e a outra parte em português $(n=3)$. Também foi selecionado um artigo em espanhol $(n=1)$. Quanto às bases de dados, quatro foram retirados da sciELO, cinco da BVS e três da PubMed.

Dentre as 11 publicações selecionadas, foram observados que quatro estudos se tratava de artigos de revisão (duas revisões sistemáticas e duas revisões da literatura), dois artigos tratava-se de resumos da política, um artigo informativo, um documento técnico e dois estudos classificados como artigos originais, sendo um deles um estudo ecológico. Havia também entre a seleção, um relato e um estudo reflexivo.

Desses estudos, quatro tinham como objetivo relacionar o baixo índice de saneamento com o possível aumento dos casos de infecção por COVID-19. Quatro queriam propor resoluções ou indicações para reduzir a contaminação por SARS-CoV-2 no geral. Dois estudos avaliaram a sobrevida do vírus no trato gastrointestinal e no esgoto. E por fim, um artigo relaciona o aumento da emissão de poluentes com o aumento dos casos de COVID-19.

Quanto aos resultados dos artigos, cinco correlacionaram o número de casos de COVID-19 com o índice de tratamento de esgoto, ou que há um grande potencial para que esse vírus seja transmitido dessa forma. Cinco estudos chegaram à conclusão de que os mais suscetíveis à contaminação do SARS-CoV-2 pela via oral-fecal são as populações em vulnerabilidade social. Sete artigos apontaram que deve haver a criação de medidas que garantam o acesso ao saneamento básico para toda população para evitar a contaminação de COVID-19 por meio dessa via. Dois artigos constataram que o vírus tem baixo potencial de contaminação pela via oral fecal ou pelo esgoto sanitário. Ao analisar esses resultados, um mesmo artigo pode ter chegado a diferentes discussões, o que explica a contagem final dos resultados $(n=19)$ serem maiores que os números de artigos utilizados neste estudo $(n=11)$. 


\section{DISCUSSÕES}

\subsection{Transmissibilidade do SARS-CoV-2 pelas fezes e riscos associados}

Foi constatado a presença de SARS-CoV-2 nas fezes, e que o vírus e sobrevive por mais tempo em sua forma infectante pela via oral-fecal que pela via respiratória. Estudos demonstraram que pacientes que já não estavam sendo mais considerados como transmissores da COVID-19 por apresentarem o teste PCR negativo, ainda tinham o vírus ativo em suas fezes. Assim, foi verificado que a forma contaminante do vírus persistia nas mucosas intestinais e nas excretas desses pacientes por 25 dias a mais, mesmo após ausência de sintomas respiratórios $(6,16)$.

Embora confirmada a presença do SARS-CoV-2 nas fezes, a contaminação a partir da via oral-fecal ainda não foi atestada. Todavia, alguns estudos apontam que há elevado potencial dessa forma de contaminação ocorrer, tendo em vista que já foi provada a existência do vírus em redes de esgotos e em águas residuais. O recente estudo elaborado por Medema (2020) indicou que o SARS-CoV-2 já circulava nas redes de esgotamento em regiões próximas à hospitais holandeses, sem que houvesse pacientes diagnosticados com a doença(11).

Outros estudo mais recentes mostram que, o SARS-CoV-2 encontra-se em sua forma infectante por 10 dias em água da torneira a $23^{\circ} \mathrm{C}$ e mais de 100 dias a $4{ }^{\circ} \mathrm{C} \mathrm{e}$, em esgotos que não receberam tratamento, a sobrevida é de 2 a 3 dias a $23^{\circ} \mathrm{C}$. Além disso, o potencial de contaminação pode variar de acordo com a carga viral presente na população, a composição do esgoto - o qual pode ou não favorecer a sobrevida do patógeno - a temperatura em que a água foi tratada, a qualidade do tratamento do esgoto e deposição final do mesmo (10).

Ademais, outros estudos indicam que o SARS-CoV-2 pode ser transmitido também através do uso inadequado de águas residuais e aerossóis provenientes dos esgotos contaminados (17).

Essas evidências, dessa forma, destacam a importância de melhorar não só a qualidade dos serviços de saneamento básico, como também ampliar o acesso e distribuição do mesmo, pois, até o momento, a má qualidade e distribuição desigual de tais serviços ainda é uma grande questão nos países em desenvolvimento, sendo, portanto, os países que apresentam a maior vulnerabilidade para que haja o contágio por essa via, incluindo o Brasil. Segundo dados da Pesquisa Nacional de Saneamento Básico de 2018, o índice de tratamento de esgoto do país atingiu $46,3 \%$ para o esgoto gerado e $74,5 \%$ para 0 esgoto coletado. Esses indicadores corroboram para que o vírus esteja presente nesse meio e seja uma fonte importante de contaminação, pois a carga viral da população ainda é muito alta, e grande parte do esgoto não passa por tratamento e nem tem sua deposição final de forma adequada (4).

Portanto, mesmo que essa forma de contaminação não tenha sido comprovada, seu potencial de transmissibilidade coloca o Brasil e os demais países em desenvolvimento em alerta, já que sofrem com a grande precarização do saneamento básico, seja da coleta de esgoto ou tratamento de águas residuais.

\subsection{A precariedade das condições de saneamento e os grupos de risco durante a pandemia}


Dentre todas os estudos analisados, invariavelmente, todos chegaram à conclusão de que a população mais afetada é a que se encontra em estado de vulnerabilidade social, ou seja, incluem todos os indivíduos que moram em países em desenvolvimentos ou subdesenvolvidos e que estão em situação de rua ou não tem acesso aos serviços de saneamento básico, seja acesso a esgoto encanado e água tratada, ou aquelas que não tem acesso a insumos básicos de higiene pessoal. A falta desses recursos torna a situação ainda mais agravante em um período de pandemia, pois aumentam não só o potencial da contaminação pela via oral-fecal, mas também a contaminação por outras vias, como gotículas provenientes de espirros e tosses, o contato com superfícies contaminadas ou com aerossóis, o que dificulta o enfrentamento da pandemia por COVID-19 (4).

Quando analisamos a situação em que a população em vulnerabilidade social se encontra, pode ser constatado que muitos dos seus direitos estão sendo violados, especialmente no que se diz respeito a questões básicas, como habitação, e principalmente agora no contexto de pandemia, o direito à saúde. Isto ocorre porque, o Plano Nacional de Contingência para Infecção Humana pelo novo Coronavírus, cujas principais medidas são 0 isolamento social, etiqueta respiratória e higiene rigorosa das mãos, não leva em consideração a verdadeira situação de maior parte da população, que, por muitas vezes, não possuem infraestrutura adequada e nem saneamento básico suficiente, o que dificulta o cumprimento das medidas de higiene pessoal e ambiental recomendados. Muitas famílias vivem em casas pequenas e em condições que impossibilita o isolamento social em casos de contaminação de algum membro residente. Também, por muitas vezes, a principal fonte de renda da família é obtida através de trabalhos informais e presenciais que prejudicam o distanciamento social (19).

Nesse cenário, fica evidente que a população desfavorecida socioeconomicamente, não só apresenta um grande potencial para que se inicie a transmissão de SARS-CoV-2 pela via oral-fecal, como também por todas as outras vias possíveis. Embora haja alguns projetos governamentais que visam o combate à pandemia, isso demonstra a insuficiência de tais iniciativas em garantir os direitos básicos e equidade que prevê a Constituição brasileira.

\subsection{O saneamento básico e as possíveis formas para evitar a disseminação do SARS- CoV-2}

Levando em consideração o grande potencial que a forma de contaminação oralfecal vem apresentando, a desinfecção adequada dos esgotos sanitários, o tratamento de água adequado e distribuição mais igualitária, a deposição final adequada do esgoto e o aumento do acesso aos serviços de saneamento básico de qualidade são serviços que se tornam ainda mais relevante nesse contexto de pandemia.

A maneira pela qual o esgoto é tratado mostrou-se um importante meio para diminuir esse tipo de contaminação. O SARS-CoV-2 é um vírus envelopado com uma frágil membrana, sendo, portanto, menos estável em condições em que são expostos a oxidantes, calor, variações extremas de $\mathrm{pH}$, luz solar, desinfetantes comuns, matéria orgânica e outros microrganismos. Em determinadas circunstâncias, portanto, podem ser eficientes na inativação do vírus. Assim, pesquisas sugerem que a temperatura é a forma mais eficiente de destruição dos vírus, visto que sua elevação até $55^{\circ} \mathrm{C}$ por mais de 10 min é capaz de desnaturar as proteínas virais. Entretanto, na maioria das estações de tratamento de esgoto sanitário no Brasil inexistem processos de desinfecção, e quando existem, as estações apresentam a desinfecção por meio da cloração no tratamento 
secundário, o qual muitas vezes é realizado sem o controle da dosagem da substância, e sem a segurança de que a descontaminação foi eficaz (10).

Além do tratamento ineficiente do esgoto gerado, muitas pessoas não possuem acesso à água potável ou à água tratada para o uso cotidiano, o que impede que se protejam de forma correta do coronavírus e qualquer outra patologia que pode ser transmitida pelas mesmas vias. Mesmo com os programas governamentais como Water Sanitation and Hygiene (WASH), que tem por objetivo ampliar a distribuição de água tratada e potável, ainda não conseguiu cobrir toda a população em estado de vulnerabilidade, mostrando que esses programas devem ser concomitantes a outras medidas, para que maior parte da população tenha o acesso garantido.

Com isso, as medidas chaves para que a contaminação por essas vias possa ser evitada, é assegurar o acesso mínimo a quantidade de água potável e saneamento básico, para que assim haja subsídios para a higiene necessária durante a pandemia. Adotar abordagens alternativas de fornecimento de soluções de emergência para domicílios sem encanamento e aos que não tem lar fixo, além de garantir a disponibilidade de produtos básicos de higiene e para tratamento de água domiciliar (21). 


\section{CONCLUSÃO}

Devido à atual insuficiência de evidências sobre a relevância da transmissão fecaloral do SARS-CoV-2, este artigo de revisão levanta a necessidade de pesquisas mais aprofundadas para verificar o papel real das intervenções de saneamento e água na prevenção dessa via de transmissão. Se confirmada a hipótese fecal-oral de transmissão viral, intervenções associadas ao fornecimento de água potável e saneamento adequado devem ser, o mais rápido possível, adicionadas às estratégias atuais para o controle pandêmico da COVID-19, além da importância já reconhecida da água para lavar as mãos. Entretanto, em vista que o Brasil é um dos países em que ainda há um déficit significativo nos índices de saneamento básico e distribuição de água potável, e que tal fato pode trazer consequências de longo prazo para a saúde pública e para as estratégias de controle da pandemia, a possível contenção da COVID-19 por meio do acesso a esses serviços é, por si só, uma justificativa para estabelecer medidas imediatas para conter a exposição da população que vive nas situações mais vulneráveis a doenças de transmissão fecal-oral. 


\section{REFERÊNCIAS}

1. Salzberger B, Buder F, Lampl B, Ehrenstein B, Hitzenbichler F, Hanses F. Epidemiologie von SARS-CoV-2-Infektion und COVID-19 [Epidemiology of SARSCoV-2 infection and COVID-19]. Internist (Berl). 2020 Aug;61(8):782-788. German. doi: 10.1007/s00108-020-00834-9. PMID: 32548652; PMCID: PMC7296906.

2. Zhong BL, Luo W, Li HM, Zhang QQ, Liu XG, Li WT, Li Y. Knowledge, attitudes, and practices towards COVID-19 among Chinese residents during the rapid rise period of the COVID-19 outbreak: a quick online cross-sectional survey. Int J Biol Sci. 2020 Mar 15;16(10):1745-1752. doi: 10.7150/ijbs.45221. PMID: 32226294; PMCID: PMC7098034.

3. Ge H, Wang X, Yuan X, Xiao G, Wang C, Deng T, Yuan Q, Xiao X. The epidemiology and clinical information about COVID-19. Eur J Clin Microbiol Infect Dis. 2020 Jun;39(6):1011-1019. doi: 10.1007/s10096-020-03874-z. Epub 2020 Apr 14. PMID: 32291542 ; PMCID: PMC7154215.

4. SILVA, Renata Rocha da et al . Coronavirus disease and basic sanitation: too early to be worried?. Rev. Soc. Bras. Med. Trop., Uberaba, v. 53, e20200345, 2020

Available from <http://www.scielo.br/scielo.php?script=sci arttext\&pid=S0037$86822020000100656 \& \operatorname{lng}=$ en\&nrm=iso $>$. access on 09 Oct. 2020 . Epub July 20, 2020. https://doi.org/10.1590/0037-8682-0345-2020.

5. Organização Pan-Americana da Saúde. Folha informativa COVID-19 - Escritório da OPAS e da OMS no Brasil. Disponível em: <https://www.paho.org/pt/covid19 >. Acesso em: 9 de set. de 2020.

6. Mesoraca, A., Margiotti, K., Viola, A., Cima, A., Sparacino, D., \& Giorlandino, C. (2020). Evaluation of SARS-CoV-2 viral RNA in fecal samples. Virology Journal, 17(1). doi:10.1186/s12985-020-01359-1

7. COVID, C. (2020). Diretrizes para Diagnóstico e Tratamento da COVID-19.

8. Islam MS, Rahman KM, Sun Y, Qureshi MO, Abdi I, Chughtai AA, Seale H. Current knowledge of COVID-19 and infection prevention and control strategies in healthcare settings: A global analysis. Infect Control Hosp Epidemiol. 2020 Oct;41(10):11961206. doi: 10.1017/ice.2020.237. Epub 2020 May 15. PMID: 32408911; PMCID: PMC7253768.

9. Instituto Brasileiro de Geografia e Estatística. Pesquisa Nacional de Saneamento Básico. Disponível em <https://cidades.ibge.gov.br/brasil/pesquisa/30/84366>. Acesso em: 9 de set. de 2010.

10. Rollemberg, S., de Barros, A. N., \& de Lima, J. P. M. (2020). Avaliação da contaminação, sobrevivência e remoção do coronavírus em sistemas de tratamento de esgoto sanitário. Revista Tecnologia, 41(1).

11. Gormley, M., Aspray, T. J., \& Kelly, D. A. (2020). COVID-19: mitigating transmission via wastewater plumbing systems. The Lancet. Global health, 8(5), e643. https://doi.org/10.1016/S2214-109X(20)30112-1

12. Teixeira, Júlio César, Oliveira, Guilherme Soares de, Viali, Amanda de Mello, \& Muniz, Samuel Soares. (2014). Estudo do impacto das deficiências de saneamento básico sobre a saúde pública no Brasil no período de 2001 a 2009. Engenharia Sanitaria e Ambiental, 19(1), 87-96. https://dx.doi.org/10.1590/S141341522014000100010 .

13. Soares, A. F. S., Nunes, B. C. R., Costa, F. C. R., Silva, L. F. D. M., \& Souza e Souza, L. P. (2020). Surveillance of the sanitary sewage system and SARS-CoV-2 in Brazil: a necessary discussion. In Surveillance of the sanitary sewage system and SARSCoV-2 in Brazil: a necessary discussion. 
14. Mesía V. "PLAN DE INTERVENCIÓN DEL MINISTERIO DE SALUD PARA COMUNIDADES INDÍGENAS Y CENTROS POBLADOS RURALES DE LAAMAZONIA PERUANA FRENTE A LA EMERGENCIA DEL COVID-19" Lima; Perú. Ministerio de Salud; 20200500. 29 p. graf.

15. Global WASH Cluster, Sanitation and Water for All (SWA), UNICEF, ICRC, 2020.COVID-19 and WASH: Mitigating the socio-economic impacts on the Water, Sanitation and Hygiene (WASH) Sector. Advocacy for WASH in COVID-19.Goldman, E., 2020. Exaggerated risk of tr

16. World Health Organization. (2020). Transmission of SARS-CoV-2: implications for infection prevention precautions: scientific brief, 09 July 2020 (No. WHO/2019nCoV/Sci_Brief/Transmission_modes/2020.3). World Health Organization.

17. Odih, Erkison E., et al. "Could Water and Sanitation Shortfalls Exacerbate SARSCoV-2 Transmission Risks?." The American Journal of Tropical Medicine and Hygiene (2020): tpmd200462.

18. Anser, Muhammad Khalid et al. "Does communicable diseases (including COVID-19) may increase global poverty risk? A cloud on the horizon." Environmental research vol. 187 (2020): 109668. doi:10.1016/j.envres.2020.109668.

19. Christoffel, Marialda Moreira, et al. "Children's (in) visibility in social vulnerability and the impact of the novel coronavirus (COVID-19)." Revista brasileira de enfermagem 73 (2020).

20. de Mello, Rafael Reis Pereira Bandeira, et al. "DESAFIOS NO ACESSO À ÁGUA E SANEAMENTO BÁSICO NO BRASIL E O CONTROLE DA COVID-19." Revista Augustus 25.51 (2020): 281-293.

21. Howard, G., Bartram, J., Brocklehurst, C., Colford, J. M., Jr, Costa, F., Cunliffe, D., Dreibelbis, R., Eisenberg, J., Evans, B., Girones, R., Hrudey, S., Willetts, J., \& Wright, C. Y. (2020). COVID-19: urgent actions, critical reflections and future relevance of 'WaSH': lessons for the current and future pandemics. Journal of water and health, 18(5), 613-630. https://doi.org/10.2166/wh.2020.162. 